\title{
ADVANTAGES OF BACKWARD PEDALING TO DETERMINE THE FUNCTIONAL ABILITY OF HYPERTROPHY ARTHRITIS KNEE JOINT
}

\author{
R. Subbulakshmi1 , K. Palaniyappan², T. Gomathi Priyadharsini3 ${ }^{3}$, S. Gokulanathan ${ }^{4}$, A. Saranya ${ }^{5}$ \\ ${ }^{1}$ Reader, Department of Anatomy, Vivekanandha Dental College for Women. \\ ${ }^{2}$ Senior Lecturer, Department of Anatomy, Vivekanandha Dental College for Women. \\ ${ }^{3}$ Senior Lecturer, Department of Anatomy, Vivekanandha Dental College for Women. \\ ${ }^{4}$ Prinicipal, Vivekanandha Dental College for Women. \\ 5 Senior Lecturer, Department of Anatomy, Vivekanandha Dental College for Women.
}

\section{ABSTRACT}

\section{BACKGROUND}

Biomechanical effects of backward pedaling within 45 degrees of knee flexion without resistance in hypertrophy arthritis knee joint were examined.

\section{OBJECTIVE}

Advantages of backward pedaling to determine the functional ability of hypertrophy arthritis knee.

\section{SETTINGS AND DESIGN}

In this study, 10 patients with the age of 45-50 years of hypertrophic arthritis in knee joint were selected. Pre-test and post-test experimental group design was used.

\section{METHODS AND MATERIALS}

The selected patients were advised to perform backward pedaling within 45 degrees of knee flexion without resistance with the duration of ten minutes per day for 3 weeks. The Lysholm's knee rating scale was a measurement tool used for this study. The measurement was recorded for Pre-test on $1^{\text {st }}$ day and for Post-test on $21^{\text {st }}$ day respectively.

\section{STATISTICAL ANALYSIS}

The rate of progression in improvement in these days was calculated and the results are statistically significant at $95 \%$ level, when paired t-test was done.

\section{CONCULSION}

Back pedaling within 45 degrees of knee flexion have the biomechanical functions of increasing the moment arm of quadriceps femoris, length-tension relationship, eccentric contraction with less or no patellofemoral and tibiofemoral compression forces, activate the quadriceps femoris to generate the greatest torque is effective in the improvement of functional ability in hypertrophy arthritis knee.

\section{KEYWORDS}

Quadriceps Femoris, Backward Pedaling, Hypertrophy Arthritis, Knee Joint, Torque, Moment Arm.

HOW TO CITE THIS ARTICLE: R. Subbulakshmi, K. Palaniyappan, T. Gomathi Priyadharsini, S. Gokulanathan, A. Saranya. "Advantages of Backward Pedaling to Determine the Functional Ability of Hypertrophy Arthritis Knee Joint." Journal of Evolution of Medical and Dental Sciences 2015; Vol. 4, Issue 95, November 26; Page: 16098-16101, D0I: 10.14260/jemds/2015/2354.

\section{INTRODUCTION}

Hypertrophic arthritis is a non-inflammatory degenerative disorder of joints characterized by progressive deterioration of the articular cartilage and formation of new bones (Osteophytes) predominantly in old age group.[1] Some studies show that a progressive increase in prevalence of osteoarthritis is seen with increasing age, less than 45 years of age only $2 \%$ had osteoarthritis and between the ages of 45 to 64 years $30 \%$ had osteoarthritis and more than 65 years it was $68 \%$ prevalence.

Financial or Other, Competing Interest: None.

Submission 08-11-2015, Peer Review 09-11-2015,

Acceptance 16-11-2015, Published 26-11-2015.

Corresponding Author:

Dr. R. Subbulakshmi,

Reader in Department of Anatomy,

VDCW, Tiruchengonde,

Namakkal-(Dt)-637205,

Tamilnadu.

E-mail: ursubbulakshmi@rediffmail.com

DOI:10.14260/jemds/2015/2354.
Knee joint is the common target site of hypertrophy arthritis, since it is a weight bearing joint. Knee hypertrophy arthritis is the leading cause of chronic disability in our country and this made the person unable to walk independently for even few steps. The concept of "Wear" and "Tear" is generally attributed as a cause in weightbearing joints. Various other factors like obesity, hormonal and genetic factors, which predispose to arthritis.[2] Advanced stage of hypertrophy arthritis results in restriction of range of movement, stiffness of joint and gross deformities like genu valgum, genu varum and flexion contractures. [3]

The person neglects squatting and stair climbing and there is persistance of pain even at rest. This results in limitation of functional ability of the person. Cycling is one of the most valuable techniques for treating the patient with osteoarthrosis.

The primary effects of cycling stretches the capsule and applying rhythmical movement facilitates synovial sweep across the cartilage and may help to diminish degeneration by improving nutrition and also stimulates rapid and near 
complete healing of full thickness defect in the articular cartilage.

The purpose of this study was to determine the biomechanical effects of backward pedaling within 45 degrees of knee flexion without resistance helps the person by improving the muscular strength, joint range of motion, proprioception without joint compression force. In this study, tibiofemoral and patellofemoral compression loads of knee joint with increase in knee flexion were taken from the previous studies. The rate of progression in improvement was calculated between day 1 [Pre-test] and day 12 [Post-test]. It is found to be $10.94 \%$ and the rate of progression in improvement between day 1 [Pre-test] and 21 [Post-test] was found to be $29.90 \%$, the rate of progression are statistically calculated with paired t-test shows $95 \%$ significance.

\section{MATERIALS AND METHODS \\ PARTICIPANTS}

Eligible ten subjects of both sexes with the age of 45-50 years, who had hypertrophy arthritis of knee joint. The diagnostic criteria for hypertrophy arthritis are the subjects with the symptoms of morning stiffness, knee pain, crepitus, bony swelling, muscular weakness, and radiographic findings. Exclusion criteria included patellofemoral pain, pyogenic arthritis, rheumatoid arthritis, osteomyelitis, knee injuries, bone tumors, fractures and dislocations, cardiovascular disorders, and neurological disorders.

\section{DESIGN}

The study design was pre-test and post-test without control group experimental design. The experiment was carried out in Vivekanandha Hospital and Research Center. Consent forms were signed by all the subjects to carry out this study.

\section{PROCEDURE}

The selected subjects were examined and the knee ability of the subjects was measured with Lysholm's knee rating scale on the first day as pre-test value. The subjects were instructed to sit in a stationary bicycle. The height of the seat was adjusted to prevent excessive knee flexion, not beyond 45 degrees, the handle bars and saddle kept at the level. The cyclist while pedaling should keep the trunk slightly inclined 10 to 15 degrees forward from straight.

The subjects were advised to perform the backward pedaling within 45 degrees of knee flexion without resistance with the pedaling rate of $40 \mathrm{rpm}$. In this study, the pedaling rate was selected from the previous studies. The duration of the treatment was ten minutes with the frequent rest of one minute for every 2 minutes of pedaling to avoid fatigue for each day for 3 weeks. At the $21^{\text {st }}$ day, the improvement in knee ability was recorded with the Lysholm's knee rating scale (Which included pain, muscle strength, range, limping) as post-test value.

\section{BIOMECHANICAL EFFECT OF CYCLING}

It is one of the closed kinetic chain exercise. Grelsamer and Klein stated that closed chain (Non-weightbearing) exercises are safest in the 0-45 degrees range. In backward pedaling within $45^{0}$ of knee flexion, the patella has the greatest effect as a pulley, maximizing the moment arm of quadriceps femoris, biomechanically at this range the muscle is capable of generating the greatest torque which improves the muscular strength.[4]
At 45 degrees of knee flexion the quadriceps muscle doing an eccentric contraction results in the use of energy to activate the muscle. As knee flexion proceeds more than $45^{\circ}$, there is more contact of patella with the femur occurs and this increases the patellofemoral compression which increase the pain and the patients feel difficult to do this exercise. In this study, during backward pedaling both tibiofemoral and patellofemoral joint reaction forces are considered and up to $45^{\circ}$ of flexion there is little or no joint reaction forces produced. The measured data for patellofemoral and tibiofemoral compression forces are used from the previous studies.

\section{Arthrokinematics of Knee Joint Femoral Condyles in Flexion}

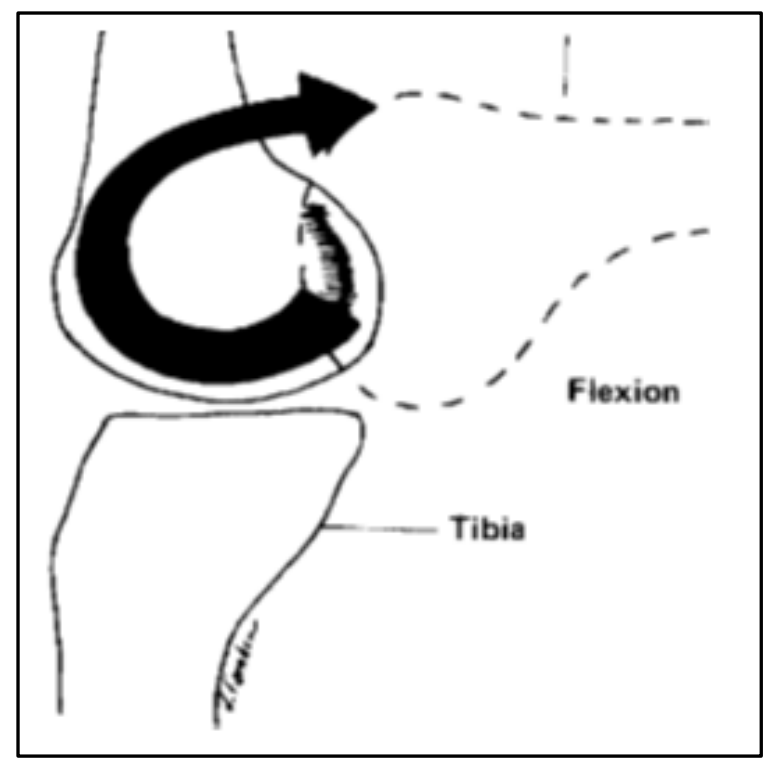

Fig. 1:1 ${ }^{\text {st }} 25^{\circ}$ Mainly Roll

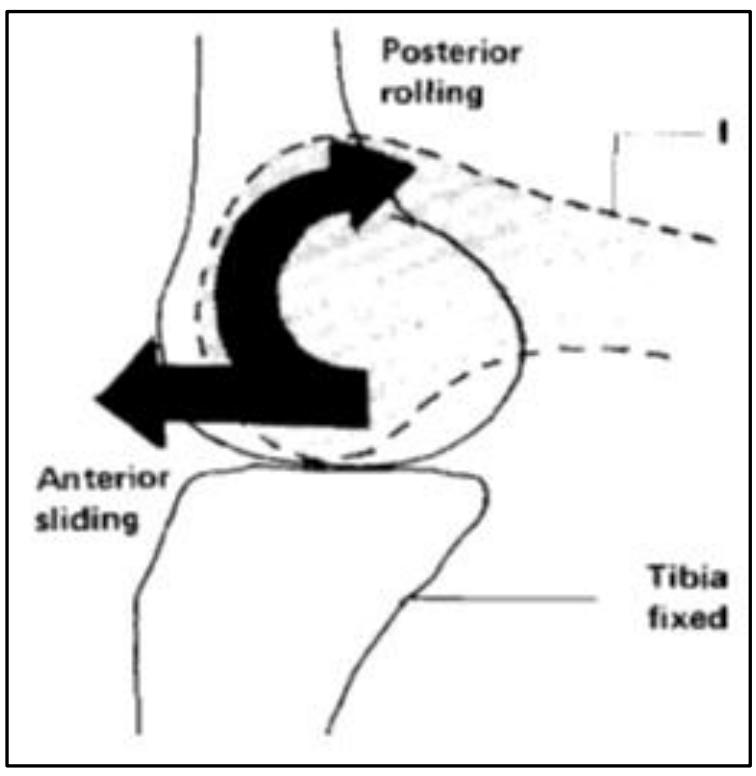

Fig. 2: >250 Roll and Anterior Glide 


\section{Soft Tissue Mechanism}

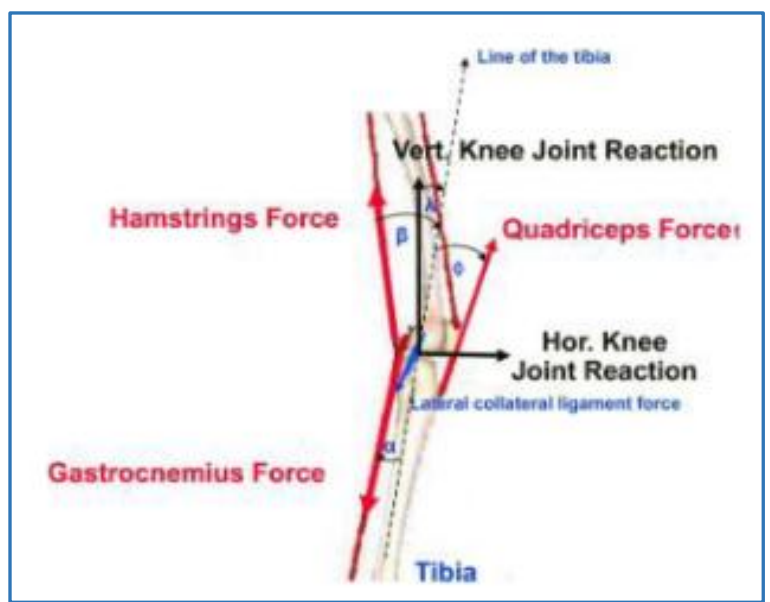

Fig. 3: Schematic Representation of the Biomechanical Musculoskeletal Knee Model used to Calculate Knee Joint Loads and Muscle Forces

Messiert S.P. et al. Ostearth Cartil 2011;19:272-280

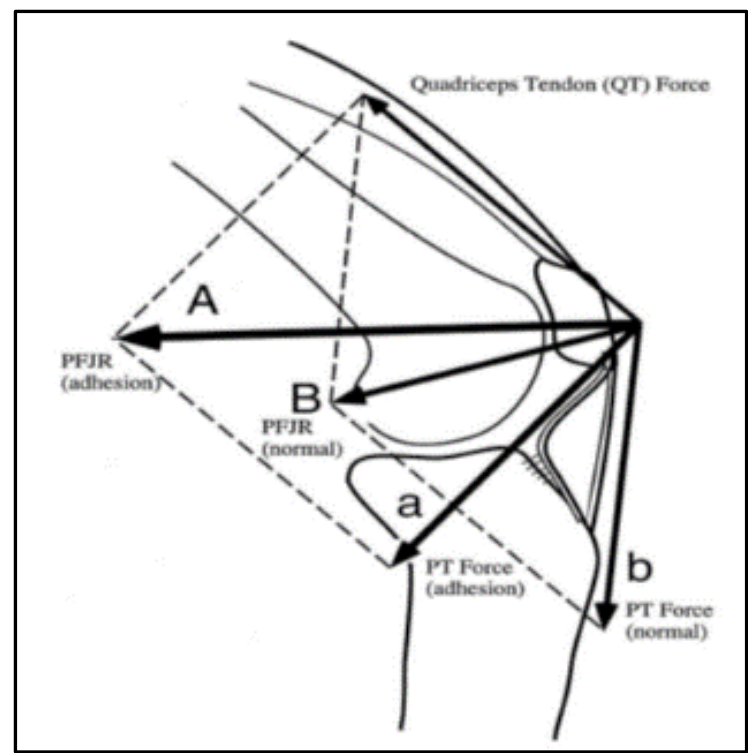

Fig. 4: Patellofemoral Joint Reaction Forces (Ahmad C.S. et al. Am. J. Sports Med. 1998;26:715-724

Right Leg of the Bicycle Rider Musculoskeletal Model

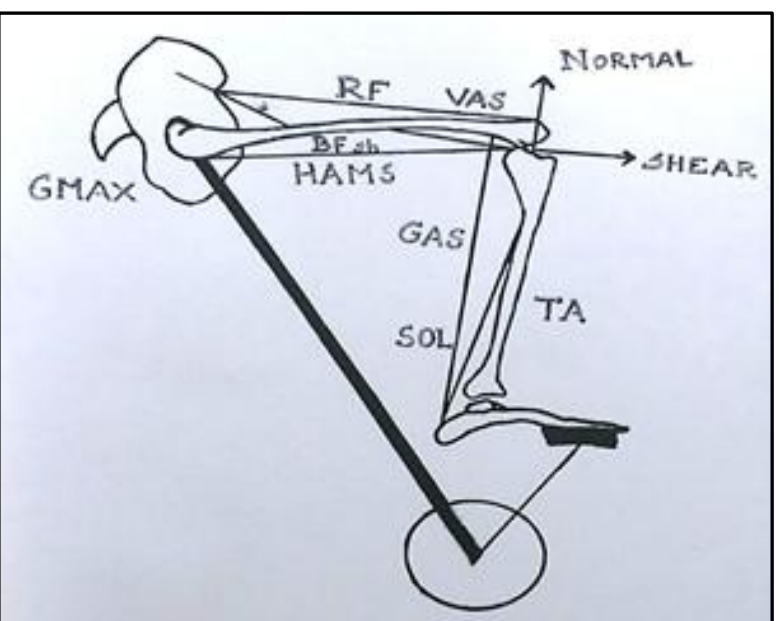

Fig. 5: R.R. Neptune, S.A. Kautz/Clinical Biomechanics 15 (2000);528-535

\section{STATISTICAL ANALYSIS FOR RESULTS}

Data was calculated from the subjects with Lysholm's knee rating scale. The first day collected data from the subjects was set as pre-test value. The post-test value was noted on $12^{\text {th }}$ day and on $21^{\text {st }}$ day. The calculated mean value for first day was 53.8 and for $12^{\text {th }}$ day the mean value was 60.7 and for $21^{\text {st }}$ day the mean was 73.6. The results show that the rate of progression in improvement between the $1^{\text {st }}$ day and for $12^{\text {th }}$ day was about $11.37 \%$. The rate of progression in improvement between $1^{\text {st }}$ and $21^{\text {st }}$ day was about $26.90 \%$.

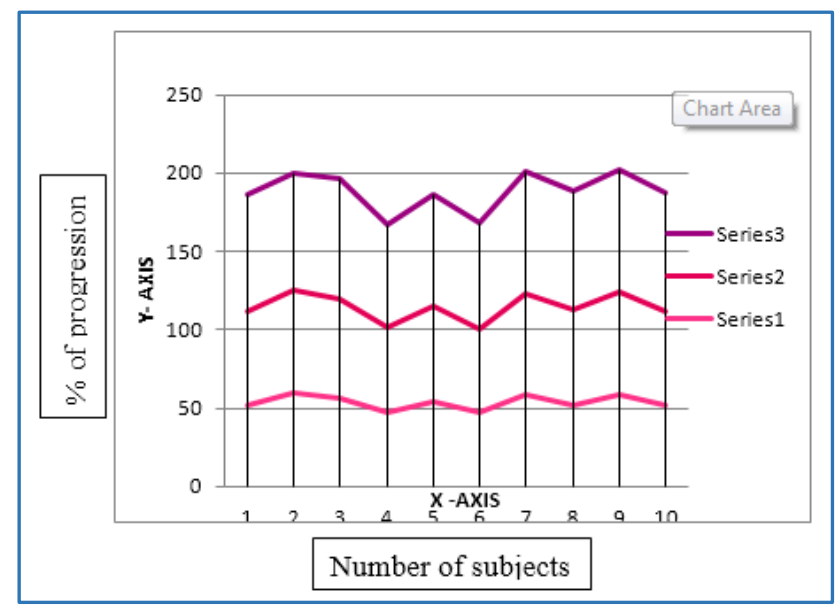

Fig. 6: Rate of Progression, Series 1- pretest value, Series 2$12^{\text {th }}$ day progression, Series 3-21st day progression

The main effect of this study was determined with the student ' $\mathrm{t}$ ' test and paired ' $\mathrm{t}$ ' test. For $1^{\text {st }}$ day and $12^{\text {th }}$ day, the ' $t$ ' value was 15.92. For 9 degrees of freedom and at $5 \%$ level of significance, the table value ' $\mathrm{t}$ ' was 2.262 and the calculated ' $t$ ' value was 15.92 , which was greater than the table value. For $1^{\text {st }}$ day and $21^{\text {st }}$ day the ' $t$ ' value was 24.331 , for 9 degrees of freedom and at $5 \%$ level of significance the table value was 2.262 and the calculated ' $\mathrm{t}$ ' value was 24.331, which was greater than the table value. Hence, there was $95 \%$ significant effect of backward pedaling in the improvement of functional ability of hypertrophy arthritis knee joint.

\section{DATA PRESENTATION}

\begin{tabular}{|c|c|c|c|c|c|}
\hline \multicolumn{2}{|c|}{} & Mean & N & $\begin{array}{c}\text { Std. } \\
\text { Deviation }\end{array}$ & $\begin{array}{c}\text { Std. Error } \\
\text { Mean }\end{array}$ \\
\hline \multirow{2}{*}{$\begin{array}{c}\text { Pair } \\
1\end{array}$} & Day12 & 60.7000 & 10 & 4.27005 & 1.35031 \\
\cline { 2 - 6 } & Day1 & 53.8000 & 10 & 4.70933 & 1.48922 \\
\hline \multirow{2}{*}{$\begin{array}{c}\text { Pair } \\
2\end{array}$} & Day21 & 73.6000 & 10 & 4.03320 & 1.27541 \\
\cline { 2 - 5 } & Day1 & 53.8000 & 10 & 4.70933 & 1.48922 \\
\hline \multicolumn{6}{|c|}{ Table 1: Paired Samples Statistics } \\
\hline
\end{tabular}




\begin{tabular}{|c|c|c|c|c|c|c|c|c|c|}
\hline & \multicolumn{5}{|c|}{ Paired Differences } & \multirow{3}{*}{$\mathbf{t}$} & \multirow{3}{*}{ df } & \multirow{3}{*}{$\begin{array}{c}\text { Sig. } \\
\text { (2-tailed) }\end{array}$} \\
\hline & & \multirow[t]{2}{*}{ Mean } & \multirow{2}{*}{$\begin{array}{c}\text { Std. } \\
\text { Deviation }\end{array}$} & \multirow{2}{*}{$\begin{array}{c}\text { Std. } \\
\text { Error } \\
\text { Mean }\end{array}$} & \multicolumn{2}{|c|}{$\begin{array}{l}\text { 95\% Confidence Interval of the } \\
\text { Difference }\end{array}$} & & & \\
\hline & & & & & Lower & Upper & & & \\
\hline $\begin{array}{c}\text { Pair } \\
1\end{array}$ & $\begin{array}{l}\text { day12 - } \\
\text { day1 }\end{array}$ & 6.90000 & 1.37032 & .43333 & 5.91973 & 7.88027 & 15.923 & 9 & .000 \\
\hline $\begin{array}{c}\text { Pair } \\
2\end{array}$ & $\begin{array}{c}\text { day21 - } \\
\text { day1 }\end{array}$ & 19.80000 & 2.57337 & .81377 & 17.95912 & 21.64088 & 24.331 & 9 & .000 \\
\hline
\end{tabular}

\section{DISCUSSION}

The main objective of this study was to find out the function of quadriceps femoris in backward pedaling within 45 degrees of knee flexion without resistance in improving the functional ability. After $3^{\text {rd }}$ week of backward pedaling for the patients with hypertrophy arthritis in knee, the results show an improvement in quadriceps femoris muscular strength, range of motion of knee, reduction in knee pain and the functional ability. BELLS and ZACHER mentioned about the importance of cycling in improving the strength of the muscles around the hip and knee range of movement of the joint and also the proprioception.

Cycling one of the valuable technique for the treatment of knee disorders. The advantages of backward pedaling within 45 degrees of knee flexion are the patella acts a pulley by increasing the moment arm of quadriceps femoris, the tibiofemoral and patellofemoral compressive loads are less, helps the person to do the pedaling without pain. The outcome measures of this study was recorded with Lysholm's knee rating scale (Included the scoring for knee pain, stability of the joint, swelling, squatting, stair climbing, locking).

Cycling with backward pedaling within 45 degrees of knee flexion without resistance had improved the above said outcome measures. R.R. Neptune and S.A. Kautz explained the patellofemoral and tibiofemoral compressive loads in knee joint during forward pedaling and backward pedaling in musculoskeletal model with resistance. The authors concluded that the backward pedaling offers reduced tibiofemoral compressive loads for those patients with knee disorders such as menisci damage and osteoarthritis, but higher patellofemoral compressive loads.

Neptune RR, Kautz SA, Zajac FE also stated the quadriceps femoris work in backward pedaling. [5] This study was mainly designed with the biomechanical consideration. Backward pedaling within 45 degrees of knee flexion, the functions of patella are increased, the mechanical advantages of the quadriceps muscle group and reduces the friction between quadriceps tendon and femoral condyles and helps to distribute the compressive forces that are placed on femur.

The patellofemoral and tibiofemoral compressive forces within 45 degrees of knee flexion are considered from the previous studies. Mangione and Kesin McCulley studied that low intensity cycling was as effective as high intensity cycling in improving function and gait, decreasing pain, and increasing aerobic capacity for the patients with knee osteoarthritis.[6] In this study, the subjects were made to perform cycling (backward pedaling) without resistance.
Ericson and Nisell analysed patellofemoral joint forces during cycling with proper attention to the height of the seat, pedaling rate and work load for the patients with patellofemoral pain syndrome.[7] This study was also considered the height of the seat, pedaling rate but without work load. There are limitations in this study. They are various resistance during pedaling can also include the range of movement and proprioception of the knee can be measured after cycling.

Biomechanical analysers can be used to measure the joint reaction forces and electromyography can also be used to record the muscular activity around knee. This study can also extend out to compare with the effects of forward pedaling with larger population for more than 3 weeks for better statistical analysis. The outcome measures recorded for this study are subjective, can also conduct with objective measurement.

\section{SUMMARY AND CONCLUSION}

The backward pedaling is effective in improving the functional activity of knee. The physician should therefore be able to detect the altered joint kinematics through joint play movement at the early stage. The therapy is concentrated not only in improving the muscle strength, endurance and mobility, but it should rather be directed to restore normal movements and muscle action at the joints.

\section{REFERENCES}

1. Harrisson, Eleventh Edition, Disorders of the immune systems, connenctive tissue and joints.

Page no.1694-1697.

2. Susan Standring, Fortieth Edition, Gray's Anatomy, the anatomical basis of clinical practice. Page no. 1403-1407.

3. Kapandji IA, Williams and Wilkins Baltimore, the physiology of the joints vol. 2. ed2.,1970.

4. Cynthia C Norkin, Pamela K. Levangie. Joint Structure and Function- A Comprehensive Analysis, second edition page no.30-54,104-112,338-375.

5. R.R. Neptune, S.A. Kautz, Rehabilitation R and D Center (153), Knee joint loading in forward versus backward pedaling implications for rehabilitation strategies. VA Palo Alto Health Care System, 3801 Miranda Avenue, Palo Alto, CA 94304, USA.

6. Manginne KK, McCully K, Glkociak A, Lefeb Vrel, Hofmann M, Crai J Gerontol A. The effects of high intensity and low intensity cycle ergometry in older adults with knee osteoarthrosis.

Bio/Sci Med Sci 1999 Apr;54(4)M:184-90.

7. Mats 0 Ericson and Ralph Nisell. Patellofemoral joint forces during ergometric cycling. PHYS THER 1987;67:1365-1369. 